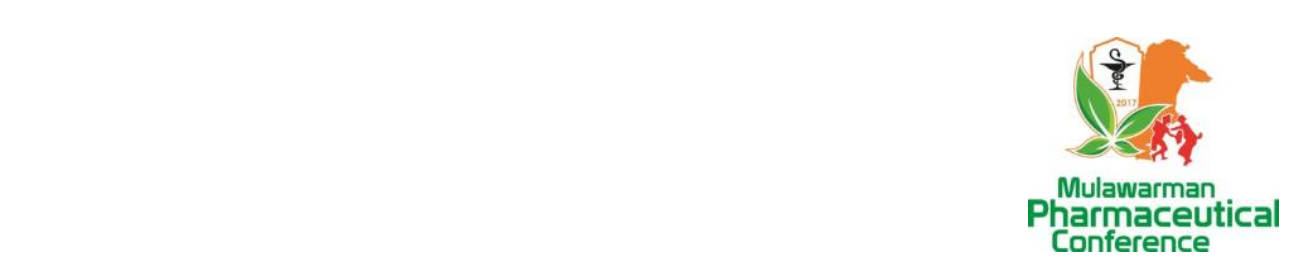

\title{
ISOLASI DAN KARAKTERISASI FUNGI ENDOFIT TUMBUHAN BROTOWALI (Tinospora crispa)
}

\author{
Elisa $^{1, \dagger}$, M. Arifuddin ${ }^{1}$, Rolan Rusli ${ }^{1,2, \sharp}$ \\ ${ }^{1}$ Laboratorium Penelitian dan Pengembangan Kefarmasian "Farmaka Tropis", \\ Fakultas Farmasi, Universitas Mulawarman, Samarinda, Indonesia \\ †Email: elisaaryanty@gmail.com \\ ${ }^{2}$ Kelompok Bidang Ilmu Kimia Farmasi, Fakultas Farmasi, \\ Universitas Mulawarman, Samarinda, Indonesia \\ *Email: rolan@farmasi.unmul.ac.id
}

\begin{abstract}
ABSTRAK
Fungi endofit adalah salah satu sumber senyawa bioaktif yang dapat menghasilkan senyawa-senyawa bioaktif yang sangat potensial untuk dikembangkan menjadi obat. Penelitian ini bertujuan untuk melihat berbagai macam jenis fungi endofit secara makroskopis dan mikroskopis dari tumbuhan Brotowali (Tinospora crispa) yang dapat menjadi kandidat dari fungi endofit yang dapat memproduksi senyawa bioaktif. Isolasi endofit dari batang Brotowali dilakukan pada medium PDA dan diperoleh 5 isolat fungi endofit.
\end{abstract}

Kata Kunci: Fungi endofit, isolasi, Brotowali (Tinospora crispa)

DOI: https://doi.org/10.25026/mpc.v7i1.291

\section{PENDAHULUAN}

Tumbuhan brotowali termasuk salah satu spesies dari genus Tinospora yang dikenal dengan nama spesies Tinospora crispa. Tinospora crispa berasal dari India dan kemudian menyebar sampai di Indonesia. Tumbuhan brotowali merupakan tumbuhan yang sudah dikenal sebagai tumbuhan obat memar, demam, merangsang nafsu makan, sakit kuning, cacingan, batuk, mencuci luka pada kulit atau gatal- gatal dan untuk mengobati penyakit kencing manis. Tumbuhan brotowali dilaporkan memiliki berbagai aktivitas biologis seperti antimalaria, antidiabetes, antipieretik, antihiperglikemik. Berdasarkan informasi ilmiah juga telah ditemukan khasiat tumbuhan brotowali yaitu ekstrak batang brotowali yang berpotensi sebagai antioksidan untuk mencegah timbulnya arterioklerosis atau sejenis penyakit kardiovaskuler [8].

Disamping itu, pada fungi endofitik batang tumbuhan Brotowali dilaporkan pula adanya senyawa hasil isolasi antara lain yaitu alkaloid, golongan piran, senyawa turunan ftalat dan senyawa turunan lakton, didapatkan pula senyawa: 7-hidroksi-3,4,5-trimethyl6-on-2,3,4,6-tetrahydroisoquinoline-8carboxylic acid dan 2,5-dihydroxy-1(hydroxymethyl) pyridin-4-on yang memiliki aktivitas sebagai antimalaria [6] dan senyawa antara lain N-cis- 
feruloyltyramine, $\mathrm{N}$-trans-

feruloyltyramine dan secoisolariciresinol yang memiliki aktivitas sebagai antioksidan [7].

Pemanfaatan keberadaan fungi endofit dalam memproduksi senyawa yang sama persis dengan inangnya tentunya lebih murah, ekonomis, dan cepat [2]. Dengan demikian, penelitian ini perlu dilakukan dalam mengidentifikasi dan mengkarakterisasi strain isolat fungi endofit yang diisolasi dari tanaman obat Tinospora crispa sehingga bermanfaat dalam mendukung produksi senyawa metabolit sekunder dari Tinospora crispa.

\section{METODE PENELITIAN}

Sampel batang tumbuhan Brotowali dikumpulkan dan dicuci secara menyeluruh dengan air mengalir, kemudian dipotong-potong menjadi bagian yang lebih kecil. Bagian tersebut dilakukan sterilisasi permukaan dengan menggunakan prosedur oleh [9] yang telah dimodifikasi. Setelah itu dikeringkan, kemudian bagian-bagian tersebut dipotong menjadi bagian kecil dengan ukuran sekitar $5 \times 5 \mathrm{~mm}$ yang dikerjakan secara aseptik. Semua hasil potongan segmen sampel dimasukkan kedalam cawan petri yang berisi medium PDA dan diinkubasi pada suhu $23 \pm 2^{\circ} \mathrm{C}$. Dilakukan pemurnian dan pengamatan secara berkala pada cawan petri hingga diperoleh isolate fungi endofit. Dihitung pula, Frekuensi tumbuh koloni fungi endofit [2]. Dihitung pula, Frekuensi tumbuh koloni jamur endofit dihitung berdasarkan [10].
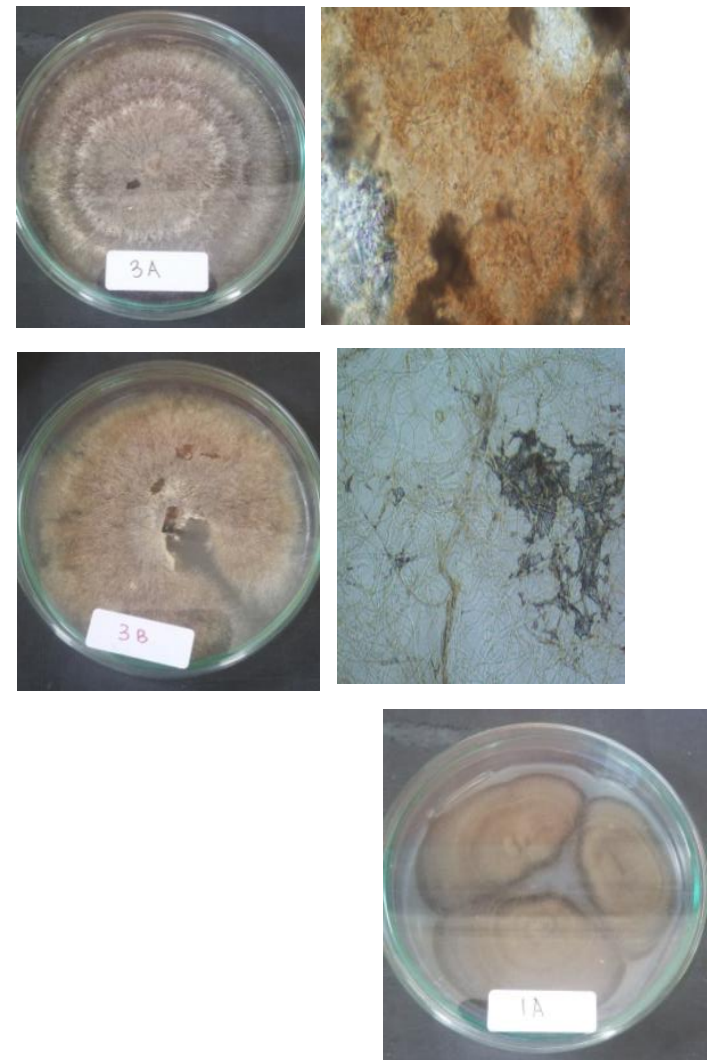
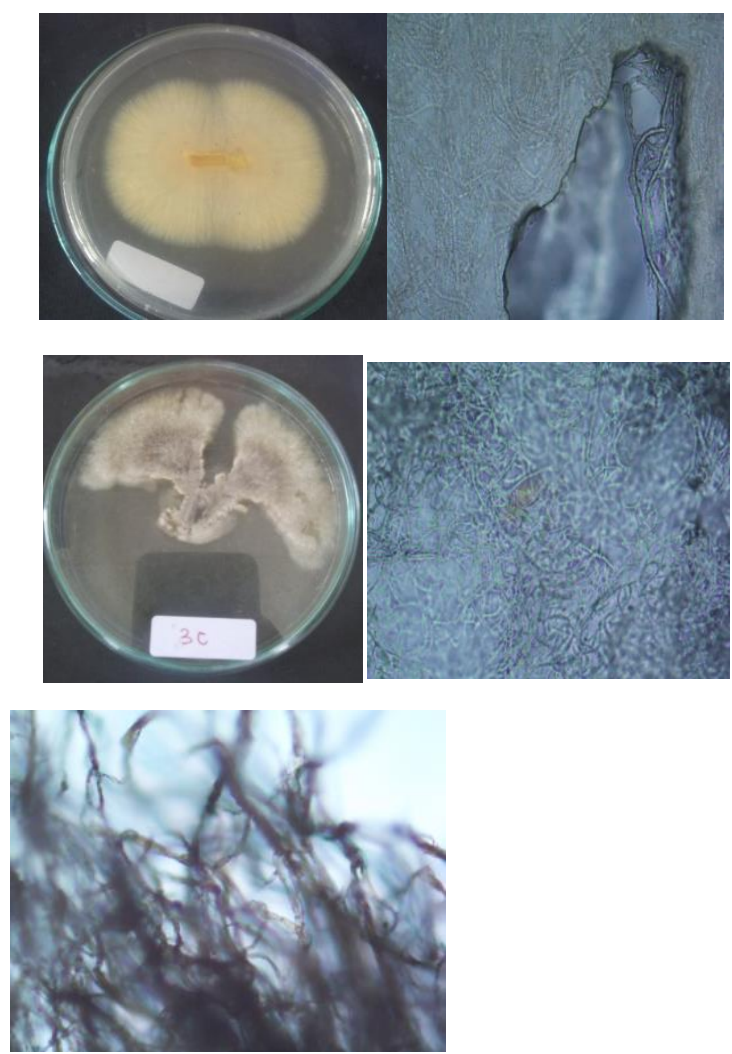

Gambar1. Hasil isolasi fungi endofit dari batang Brotowali 


\section{PEMBAHASAN}

Hasil isolasi fungi endofit dari tumbuhan Brotowali pada bagian batang diperoleh 5 isolat fungi endofit (Gambar 1) yakni TC $3 \mathrm{~A}, \mathrm{TC} 2 \mathrm{~A}$, TC $3 \mathrm{~B}, \mathrm{TC} 3$ $\mathrm{C}$, dan TC 1 A. Pengunaan medium telah disesuaikan harapannya agar fungi yang tumbuh dapat optimal. Adapun frekuensi pertumbuhan koloni fungi batang Brotowali dari segmen yang ditumbuhkan sebesar 50\%.

Isolat 3 A mempunyai ciri-ciri dengan bentuknya membentuk lingkaran teratur terdapat pula lingkaran bewarna putih dan hitam pada permukaan, memiliki spora dan koloni yang cenderung bewarna hitam. Berdasarkan hasil makroskopis dan mikroskopis tersebut sesuai dengan karakter yang dimilk oleh Phoma sp [5]

Isolat 2 A mempunyai ciri-ciri dengan bentuknya membentuk lingkaran teratur dengan koloni bewarna putih dan terdapat pula bintik -bitik bewarna kuning, bagian tengah koloni tampak seperti kapas memiliki spora dan serabutserabut halus pada tepi permukaan koloni. Berdasarkan hasil makroskopis dan mikroskopis tersebut sesuai dengan karakter yang dimilk oleh Acremonium $s p$ [5].

Isolat 3 B mempunyai ciri-ciri dengan bentuknya membentuk lingkaran tidak teratur dengan koloni bewarna kuning kecokelatan, memiliki spora dan serabut- serabut halus bewarna putih dan kuning pada tepi permukaan koloni. Berdasarkan hasil makroskopis dan mikroskopis tersebut sesuai dengan karakter yang dimilk oleh Penicillum $s p$ [4].

Isolat $3 \mathrm{C}$ mempunyai ciri-ciri dengan bentuknya yang tidak teratur dengan koloni bewarna putih keabuabuan, memiliki spora dan serabutserabut halus bewarna putih pada tepi permukaan koloni. Berdasarkan hasil makroskopis dan mikroskopis tersebut sesuai dengan karakter yang dimilki oleh Phoma sp [5].
Isolat 1 A mempunyai ciri-ciri dengan bentuknya menyerupai lingkaran dengan koloni bewarna hitam kehijauan dan terdapat serabut-serabut halus pada tengah koloni dan serabut hitam pada tepi koloni. Berdasarkan hasil makroskopis dan mikroskopis tersebut sesuai dengan karakter yang dimilk oleh Colletotrichum $s p$ [5].

\section{KESIMPULAN}

Berdasarkan hasil makroskopik dan mikroskopik diperoleh 5 fungi endofit dari tumbuhan Brotowali (Tinospora crispa) dimana salah satu isolat yang telah diidentifikasi memiliki ciri-ciri dan karakter fungi Phoma $s p$, Acremonium sp, Penicillum sp. dan Colletotrichum sp. dengan frekuensi tumbuh koloni segmen batang adalah $50 \%$.

\section{DAFTAR PUSTAKA}

[1] Akmalasari, Iva., Endang Sri. P., Ratna Stia. D. 2013. Isolasi dan Identifikasi Jamur Endofit Tanaman Manggis (Garcinia mangostana L). (82-89)

[2] Arifuddin, M., Bone, M., Iswahyudi., Ibrahim, A., Rija, L. Isolasi dan Karakterisasi Fungi Endofit Tanaman Tapak Dara (Catharanthus roseus).2017.

[3] Barber, P.A., T. J. Burgess, G. St. J. Hardy, B. Sliper, P. J. Keane and M. J. Wingfield. 2005. Botryosphareria Spacies From Eucalyptus in Australia are Pleoanamorphic, Producing Dichomera Synanamorphs in Culture. Mycol. Res, 109 (12): 1347-1363.

[4] Barnett, H. L. and B. B. Hunter. 1972. Illustrated Genera of Imperfect Fungi. Third Edition. Burgess Publishing. Company, Minnesote.

[5] Domesch, K. H. and W. Gams. 1980. Compendium Of Soil Fungi Volume 1. Academic Press, London.

[6] Elfita, Muharni., Munawar, Leni Legasari, and Darwati. 2011. 
Antimalarial Compounds From

Endophytic Fungi of Brotowali (Tinaspora crispa L). Indo. J. Chem., 2011, 11 (1), 53 - 58

[7] Elfita, Munawar, Muharni, and Sudrajat, M.A. 2014. Identification of New Lactone Derivatives Isolated from Trichoderma sp., An Endophytic Fungus of Brotowali (Tinospora crispa). Hayati Journal of Bioscience. 21 (1), 15-20) .

[8] Kamarazaman, I.S., Amom, Zulkhairi, HJ., Ali, R.M., Akim, A.MD., Azman, K.F., Arapoc, D.J., Hassan, M.K.N., Arshad, M.S.M, Shah, Zamree.Md., and Kadir, K.K.A. 2012. Inhibitory Properties of Tinospora crispa Extracs on TNF - $\grave{\alpha}$ Induced
Inflammation on Human Umbilical Vein Endothelial. International Journal of Tropical Medicine. 7 (1): $24-29$.

[9] Roopa, G., Madhusudhan, M.C., Sunil, K.C.R., Lisa, N., Calvin, R., Poornima, R., Zeinab, N., Kini, K.R., Prakash, H.S., Geetha, N. 2015. Journal of Genetic Engineering and Biotechnology.

http://dx.doi.org/10.1016/j.jgeb.2015 .09 .002

[10] Suryanarayanan, T. S., Venkatesan G. and Murali T. S. 2003. Endophytic fungal communities in leaves of tropical forest trees: Diversity and distribution patterns. Current Science. Vol. 85. No. 4. 489492. 